Quebec Cooperative Study

of Friedreich's Ataxia

\title{
Urodynamic Evaluation of Patients with Hereditary Ataxias
}

\author{
J.G. VEZINA, J.P. BOUCHARD, R. BOUCHARD
}

\begin{abstract}
Seventeen patients with Friedreich's ataxia or spastic ataxia were subjected to an urodynamic evaluation. Fifty-three per cent (53\%) of the patients presented with urinary symptoms consisting of urgent micturition and urgency incontinence. Cystometric evaluation showed a lack of inhibition of the detrusor in 7 patients (41\%). Abnormal electric hyperactivity of the external sphincter was documented in 6 cases $(37.5 \%)$ by electromyography. Some hypotheses are presented to explain the etiology of these abnormal findings.
\end{abstract}

RÉSUMÉ: Une étude urodynamique a été faite chez 17 patients atteints d'ataxie de Friedreich et d'ataxie spastique familiale. Une symptomatologie urinaire est rencontrée chez $53 \%$ (9 cas) de ces patients et est faite surtout d'urgence mictionnelle avec incontinence secondaire. La cystométrie est anormale dans $41 \%$ ( 7 cas) des cas et montre, en général, un défaut d'inhibition. L'électromyographie globale du sphincter externe montre une activité électrique nettement augmentée dans $37.5 \%$ (6 cas) des cas. Des hypothèses étiologiques sont proposées.

From l'Hôpital de l'Enfant-Jésus, Quebec City.

Reprint Requests for the complete supplement (Phase Three, Part Two) to: Prof. Andre Barbeau, Clinical Research Institute of Montreal, 110 Pine Avenue West, Montreal, Quebec, Canada H2W 1R7.

\section{INTRODUCTION}

Bladder and bowel problems have received little attention in early and recent studies of patients with various forms of hereditary ataxia. Briefly accounted for in the review of Bell and Carmichael (1939), they were classified with other autonomic changes and it was stated that they "had been so rarely recorded that their occasional association with the disease seemed of little significance and perhaps accidental". (Tyrer, 1975). Occasional cases were reported to be incontinent in some other pedigrees of hereditary ataxia.

No mention of sphincter disturbance was made in the clinical description of the first fifty patients evaluated at the beginning of the Quebec cooperative study on Friedreich's ataxia (Geoffroy et al, 1976). But later in the course of this study, attention was drawn to urine urgency and incontinence in almost $50 \%$ of patients when looked for (Bouchard et al, 1978, 1979). An urodynamic investigation was devised to better understand the problem as well as to help the patients concerned with it.

\section{MATERIAL AND METHODS}

Of the seventeen patients included in this report, 9 had Friedreich's ataxia. Seven were diagnosed as spastic ataxia of Charlevoix-Saguenay and one patient presented another form of spastic ataxia. The average age of the 17 patients ( 9 females and 8 males) was 27.1 years (range sixteen to forty-one years).

\section{SYMPTOMATOLOGY}

As mentioned earlier, a study by Bouchard et al (1978) has detected urinary disturbances in almost $50 \%$ of ataxic patients reported. The present study confirms these findings by show-
TABLE 1

DISTRIBUTION OF PATIENTS

Total Friedreich Spastic

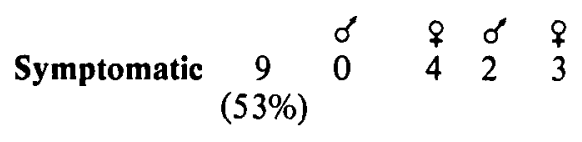

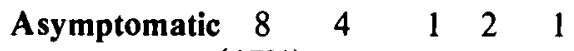

(47\%)

TABLE II

ASYMPTOMS

Total Friedreich Spastic

$\begin{array}{llll}\text { Urgency } & 7 & 3 & 4 \\ \text { Incontinence } & 7 & 3 & 4 \\ \text { Pollakyuria } & 2 & 1 & 1 \\ \text { Nycturia } & 3 & 1 & 2\end{array}$

ing that 9 cases of the 17 patients studied $(53 \%)$ had urinary problems. Of these 9 patients, 4 were female with Friedreich's ataxia and 5 ( 3 males and 2 females) had the diagnosis of spastic ataxia (Table I).

The symptomatology consisted mainly of urgency with secondary incontinence sometimes associated with frequency and nocturia (Table II). Urinary infection was found in only one patient with a positive culture and symptoms were completely relieved by antibiotic administration. Three other patients had to receive active treatment because of severe symptoms. One incontinent female patient is on indwelling catheter due to failure of anticholinergic drugs to correct incontinence. One female patient is greatly improved with the administration of oxybutinine chloride. These two patients presented with uninhibited detrusor contractions on cystometric study. Finally, a third case with un- 
inhibited neurogenic bladder with external sphincter incoordination is partially improved with the administration of propantheline bromide and diazepam. This last patient, however, does not empty his bladder completely but has no evidence of urinary infection. The five other patients did not receive any treatment because their symptoms were of minor importance.

\section{URODYNAMIC EVALUATION}

Cystometric study was performed in all cases. Gaz cystometry was used in the early patients and then water cystometry was the method preferred for better accuracy. Global electromyography of the external sphincter with perineal needle electrode was performed during cystometry to evaluate the muscle activity and its synergia with the detrusor. Only 4 patients were able to have a satisfactory urine flow study, all others were physically unable to perform such an evaluation.

The urethral pressure profile was also done in 14 patients, but the significance of the results of this test is still too controversial to bring any useful data at this stage of the study. The UR0-2100 apparatus made by Disa Electronics was used in the present study.

\section{RESULTS}

Ten cases presented with normal cystometric study and normal bladder capacity. The absence of voluntary detrusor contraction, with normal capacity, was not considered abnormal, being probably of psychogenic origin. Three of these ten patients admitted to symptoms of urgent micturition and urgency incontinence.

Seven patients had an abnormal bladder behavior on cystometry (Table III). One patient presented with an increased bladder capacity of $600 \mathrm{ml}$ : he complained of initial dysuria and voided only twice a day. Two patients had uninhibited detrusor contractions. In three cases, the initiation of the detrusor contraction was well controlled voluntarily but during micturition voluntary inhibition was impossible (uninhibited voluntary contraction). In two of these patients, the bladder pressure during micturition was greater than $100 \mathrm{~cm}$ of water. Finally, one case
TABLE III CYSTOMETRY

- Normal .............. 10(59\%)

- Abnormal .............. 7 (41\%)

- Increased Bladder Capacity .......1

- Uninhibited Bladder ............

- Voluntary Contraction

without Inhibition $\ldots \ldots \ldots \ldots . .3$

- Diminished Capacity (Cystitis) ...1

TABLE IV

\section{ELECTROMYOGRAPHY}

- Normal ........... 10(62.5\%)

- Abnormal (Increased

Electric Activity) ...... 6(37.5\%)

With:

Complete Voluntary Relaxation ...4

Partial Voluntary Relaxation .....2

Detrusor-Sphincter Dyssynergia ...1

Clonic Contractions ..........

had a greatly diminished bladder capacity secondary to an acute cystitis confirmed by positive urine culture.

External sphincter electromyography was normal in $62.5 \%$ of the cases. Technical difficulties prevented a satisfactory EMG study in one patient. In 6 cases $(37.5 \%)$ the electric activity of the external sphincter was abnormally increased (Table IV). During bladder filling, a normal recruiting of motor units is noted. Voluntary relaxation is complete in 4 of these patients and partial in two cases. One patient presented with an obvious sphincter-detrusor dyssynergia. This patient was shown to have a significant bladder residual after micturition. In one other case, clonic sphincter contractions were noted during micturition.

Finally, only one patient had a normal uroflowmetry among the 4 patients who were able to be studied, with a voided volume greater than $250 \mathrm{ml}$. Three patients showed a maximum flow rate of less than $15 \mathrm{ml} / \mathrm{sec}$. In these patients the graph shows interruptions compatible with abdominal pressure caused by Valsalva's maneu- ver. This hypothesis will be investigated soon by recording the intra-rectal pressure during uroflowmetry.

\section{DISCUSSION}

Little is known about the role of the cerebellum in human bladder control. In spinocerebellar degenerations, Greenfield (1954) had difficulties correlating pathological changes with precised clinical signs and no mention is made in his work, of the role of the cerebellum in bladder control. Both afferent fibers in the posterior column and spino-cerebellar tracts and efferent cerebellar fibers to the red nucleus, reticular formation of the medulla and vestibular nuclei are markedly damaged in these diseases and probably play a role in bladder physiology. A more recent pathological study in Friedreich's ataxia by Oppenheimer (1979) did not shed more light on this matter. A review of cerebellar physiology and pathology by Ito (1978) identified numerous functional subsystems involving the cerebellum, but nothing is said about bladder function.

Bradley has been interested in cerebellar, spinal and peripheral influences on the bladder. He has shown a detrusor reflex activation dependant upon the brain stem reticular formation (Bradley, 1969) and a cerebellar inhibitory action on the same muscle (Bradley and Teagne, 1969). Bradley et al, (1974) developed a comprehensive concept of micturition reflex. Most of the work was done in cats and correlation of their studies with the clinical findings anticipated hyperactive or uninhibited bladder contractions, but they stated that, instead, the case reports had stressed bladder atony in most cases of cerebellar diseases.

The present urodynamic evaluation of ataxic patients favors a central nervous system lesion affecting voluntary inhibition of the detrusor. The cerebellar and associated lesions reported in patients with Friedreich's ataxia (Oppenheimer, 1979) could support the etiologic explanation of bladder symptoms and cystometric findings reported in the present study. Furthermore, the lesions noted in the pyramidal tract could be responsible for the abnormal external sphincter behaviour, especially 
in those two cases with clonic contractions or bladder-sphincter dyssynergia. No definite sign of bladder proprioceptive anomaly was detected in the present studies.

Further studies should be aimed at more detailed investigation of patients who are only symptomatic, in order to better define and understand bladder functions in hereditary ataxia and to propose early suitable medication in both hyperactive or atonic bladders to prevent further damages.

\section{ACKNOWLEDGEMENTS}

These studies were supported by grants from l'Association canadienne de l'Ataxie de Friedreich. We wish to thank Dr. J.P. Paquet for his advice and Mrs. A. LaBrecque and A. Landry for their assistance.

\section{REFERENCES}

BELL, J.M. and CARMICHAEL, E.A. (1939). On hereditary Ataxia and Spastic Paraplegia. In: Treasury of Human Inheritance, Vol. 4, Cambridge Press, London, pp 141284.

BOUCHARD, J.P., BARBEAU, A., BOUCHARD, R. and BOUCHARD, R.W. (1978). Autosomal Recessive Spastic Ataxia of Charlevoix-Saguenay. Canadian Journal of Neurological Sciences, Vol. 5: 61-70.

BOUCHARD, J.P., BARBEAU, A., BOUCHARD, R., PAQUET, $M$. and BOUCHARD, R.W. (1979). A Cluster of Friedreich's Ataxia in Rimouski, Québec. Canadian Journal of Neurological Sciences, 6: 205-208.

BRADLEY, W.E. (1969): Micturition Reflex Amplification. Journal of Urology, 101: 403-407.

BRADLEY, W.E. and TEAGNE, C. (1969). Cerebellar Regulation of the Micturition Reflex. Journal of Urology 101: 396-399.
BRADLEY, W.E., TIMM, G.W. and SCOTT, F.B. (1974). Innervation of the Detrusor Muscle and Urethra. Urol. Clin. N. Amer., Vol. 1, No. 1: 3-27.

GEOFFROY, G., BARBEAU, A., BRETON, G., LEMIEUX, B., AUBE, M., LEGER, C. and BOUCHARD, J.P. (1976). Clinical Description and Roentgenologic Evaluation of Patients with Friedreich's Ataxia. Canadian Journal of Neurological Sciences, 3: 279-286.

GREENFIELD, J.G. (1954). The Spinocerebellar Degeneration. Blackwell Scient. Publ., Oxford.

ITO, M. (1978). Recent Advances in Cerebellar Physiology and Pathology. In: Advances in Neurology, Vol. 21, Raven Press, New York, pp. 59-84.

OPPENHEIMER, D.R. (1979). Brain Lesions in Friedreich's Ataxia. Canadian Journal of Neurological Sciences, 6: 173-176.

TYRER, J.H. (1975). Friedreich's Ataxia. Handbook of Clinical Neurology, 21:319384. 